\title{
ESTUDO DO PARCELAMENTO DA ADUBAÇÃO POTÁSSICA DO ALGODOEIRO ( $\left.{ }^{1}\right)$
}

\author{
NELSON MACHADO DA SIEVA (2), LUIZ HENRIQUE CARVALEO ( 2 ), EDIVALDO CIA (2) \\ EDERALDO JOSÉ CHIAVEGATO (2), Seção de Algodão, e JOSÉ CARLOS SABINO (2) \\ Estaçâo Experimental de Tietê, Instituto Agronômico.
}

\section{RESUMO}

Em dez experimentos de campo conduzidos com o algodoeirc no Estado de São Paulo, no período compreendido entre os anos agtícolas de 1975/76 e 1980/81, estudou-se a conveniência de parcelar a aplicação de cloreto de potássio. Foram aplicadas no sulco de semeadura, em posição lateral e em nivel inferior ao das sementes, as doses de 0,60 e $120 \mathrm{~kg} / \mathrm{ha}$ de $\mathrm{K}, \mathrm{O}$. Nos demais tratamertos, a dose de $120 \mathrm{~kg} /$ ha ou parte dela $(1 / 3,172$ e $2 / 3)$ foi aplicada em cobertura, após o desbaste, em mistura com o adubo nitrogenado, com incorporação na operação de "chegar terra". Na análise individual dos resultados de produção de algodão em caroço, em apenas $10 \%$ dos casos houve efeito linear de potássio, quando aplicado tradicionalmente. Com o parcelamento, esse número subiu para $40 \%$. Entretanto, no conjunto dos ensaios, a diferença entre modos de aplicaçāo åo nutriente não foi estatisticamente significativa. Os ensaios foram reagrupados em função de resultados dos estudos de correlação entre a produção relativa $(P R)$ da testemunha $(P R=100 \times$ produção sem potássio/produção com potássio) e índices de análise de solo. Estabeleceram-se grupos de respostas esperadas nos estudos de correlação linear entre $\mathrm{PR}$ e os índices analíticos mais relacionados com a resposta das plantas à ađubação, que foram, em ordem decrescente de importancia, $\left(\mathrm{Ca}^{2}++\mathrm{Mg}^{2+}\right) / \mathrm{K}+\mathrm{e} \mathbf{1} / \mathbf{K}+$. No grupo de alta resposta esperada a potássio $\left[K+<0,08 \mathrm{meq}\right.$ e $\left(\mathrm{Ca}^{2}++\right.$ $\left.\mathrm{Mg}^{2+}\right) / \mathrm{K}^{+}>43$ ], o parceamento da dose de $120 \mathrm{~kg} /$ ha de $\mathrm{K}_{2} \mathrm{O}$ superou a forma tradicional de aplicação; no grupo de média resposta esperada $\left[0,08\right.$ a $0,24 \mathrm{meq}$ para $\mathrm{K}+\mathrm{e}\left(\mathrm{Ca}^{2}++\mathrm{Mg}^{2+}\right) /$

(1) Recebido para publicação a 13 de setembro de 1982.

(2) Com bolsa de suplementação do CNPq. 


\begin{abstract}
$/ \mathrm{K}^{+}$, na faixa de $20-43$ ], notou-se clara tendência para maior efeito da aplicação parcelada. Dessa forma, recomenda-se que, em condições de deficiência potássica, a aplicação de cloreto de potássio seja parcelada com cerca de $1 / 2$ a $2 / 3$ da dose no sulco de plantio (ao lado e em nivel inferior ao das sementes) e o restante em cobertura, após o desbaste, com o adubo nitrogenado, com incorporação da mistura na operação de "chegar terra".
\end{abstract}

\title{
1. INTRODUÇĀO
}

A época e o modo mais adequados de aplicação de potássio como de qualquer outro nutriente, são determinados em função da exi gência das plantas e da dinâmica do elemento no solo.

De acordo com EATON \& EARGLE (3), o algodoeiro requer, desde a mais tenra idade, um suprimento contínuo de potássio. Entretanto, fases de mais intensa absorção do nutriente foram identificadas no abotoamento das plantas e mesmo durante o florescimento, segundo MENDES (9) e OLSON \& BLEDSOE (12). CATANI (1) observou, por outro lado, que existe pouca possibilidade de fixação de potássio, sob forma inaproveitável pelas plantas, quando predomina argila do tipo caulinita, como em nossos solos. Embora exista referência sobre lixiviação sensível de potássio, em solos arenosos (8), KÜPPER et alii (7), estudando a percolação do nutriente em diferentes tipos de solo do Estado de São Paulo, demonstraram que seu caminhamento é lento.

Nos primeiros relatos sobre ensaios de épocas de aplicação de potássio, feitos por NEVES \& FREIRE (11), presumivelmente conduzidos em solos bem supridos no nutriente, não houve vantagem em parcelar a aplicação, confirmando trabalhos conduzidos em outros países. Foi sugerido, então, que se aplicasse todo o potássio na operação de plantio, norma adotada até recentemente (5).

$\mathrm{O}$ assunto, no entanto, carece de maior esclarecimento, pois trabalhos conduzidos no exterior, por COOPER \& WALLACE (2) e por ROUSE (15), aparentemente em condição de maior deficiência de potássio, não assinalam diferenças sensíveis entre épocas de aplicação de adubos. Ademais, prejuízos causados à germinação das sementes e ao desenvolvimento inicial das plantas pela proximidade do cloreto, têm sido relatados com frequiência, como nos estudos de NEVES \& FREIRE $(10,11)$ e SCHMIDT et alii (15), embora a dose utilizada raramente tivesse ultrapassado $50 \mathrm{~kg} /$ ha de $\mathrm{K}_{2} \mathrm{O}$. Ora, FREITAS et alli (4), SILVA (17) e SILVA et alii (18) demonstraram, em trabalhos subsequientes, que o algodoeiro exige quantidades bem maiores do nutriente, em determinados tipos de solo.

Com o intuito de reestudar modos e épocas de aplicação de potássio, iniciou-se, em 1972/73, uma série de ensaios de campo no Estado de São Paulo, em solos frequientemente deficientes no nutriente para o algodoeiro. No presente trabalho, são apresentados e discutidos resultados sobre o parcelamento dessa adubação. 


\section{MATERIAL E MÉTODOS}

No período de 1975/76 a 1980/81, foram conduzidos dez experimentos de campo visando estudar a possibilidade de parcelar a aplicação de cloreto de potássio na cultura do algodoeiro. Utilizaram-se solos com várias disponibilidades de potássio, conforme quadro $1\left(^{3}\right)$.

QUADRO 1 - Características dos solos utilizados no estudo de parcelamento da aplicação de potássio na cultura algodoeira, no período de 1975/76 a 1980/81, no Estado de São Paulo

\begin{tabular}{|c|c|c|c|c|c|c|c|c|c|c|}
\hline \multirow{2}{*}{ Locai } & \multirow{2}{*}{$\begin{array}{c}\text { Ano } \\
\text { Agrícola }\end{array}$} & \multirow{2}{*}{ Solo } & \multicolumn{7}{|c|}{ Análise Química } & \multirow{2}{*}{ 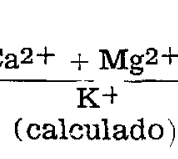 } \\
\hline & & & M.O. & $\mathrm{pH}$ & $\mathrm{Al}^{3+}$ & $\mathrm{Ca}^{2+}$ & $\mathrm{Mg}^{2+}$ & $\mathbf{K}^{+}$ & $\mathbf{P}$ & \\
\hline & & \multicolumn{3}{|c|}{$\%$} & \multicolumn{2}{|c|}{$\mathrm{meq} / 100 \mathrm{ml}$} & TFSA & \multicolumn{2}{|c|}{$\mathrm{mg} / \mathrm{ml}$} & \\
\hline 1. Guaira & $75 / 76$ & LR & 4,0 & 6,2 & - & 1,8 & 1,0 & 0,09 & 4 & 31,1 \\
\hline 2. Guará & $76 / 77$ & LR & 5,8 & 6,2 & - & 3,2 & 1,2 & 0,13 & 2 & 33,9 \\
\hline 3. Guaíra & $77 / 78$ & $\mathrm{LR}$ & 3,6 & 5,9 & - & 2,0 & 1,2 & 0,05 & 5 & 64,0 \\
\hline 4. Guaíra & $78 / 79$ & $\mathrm{LR}$ & 5,7 & 6,3 & - & 4,0 & 1,7 & 0,14 & 2 & 40,7 \\
\hline 5. Campinas & $78 / 79$ & $\mathrm{LR}$ & 2,7 & 5,2 & 0,4 & 3,0 & 0,7 & 0,17 & 8 & 21,8 \\
\hline 6. Conchal & $78 / 79$ & $\mathrm{LE}$ & 1,8 & 5,5 & 0,3 & 1,4 & 0,6 & 0,13 & 7 & 15,4 \\
\hline 7. Guará & $79 / 80$ & $\mathrm{LR}$ & 2,9 & 6,0 & - & 3,1 & 1,5 & 0,09 & 5 & 51,1 \\
\hline 8. Ituverava & $79 / 80$ & LR & 2,8 & 6,0 & - & 3,5 & 1,7 & 0,40 & 20 & 13,0 \\
\hline 9. Guará & $80 / 81$ & LR & 4,2 & 6,2 & - & 4,4 & 2,1 & 0,16 & 5 & 40,6 \\
\hline 10. Guaíra & $80 / 81$ & $\mathrm{LR}$ & 2,2 & 5,9 & 一 & 2,3 & 1,0 & 0,08 & 9 & 41,3 \\
\hline
\end{tabular}

Tendo em vista resultados obtidos preliminarmente, que indicaram como mais propícias para a adubaçāo potássica as épocas de plantio e do desbaste, foram estabelecidos os seguintes tratamentos para o presente estudo: Testemunha, sem potássio (t); $60 \mathrm{~kg} / \mathrm{ha}$ de $\mathrm{K}_{2} \mathrm{O}$, no plantio $(60 \mathrm{p}) ; 120 \mathrm{~kg} / \mathrm{ha}$, no plantio $(120 \mathrm{p}) ; 90 \mathrm{~kg} / \mathrm{ha}$, no plantio e $30 \mathrm{~kg} /$ ha, no desbaste $(90 \mathrm{p}+30 \mathrm{~d}) ; 60 \mathrm{~kg} / \mathrm{ha}$, no plantio e $60 \mathrm{~kg} / \mathrm{ha}$, no desbaste

(3) Ensaios concuzidos na Fazenda Vera Cruz, de Edson Leite de Moraes, em Guaira; na Fazenda Santa Eunice, de Américo Migliori, em Guará; no Sítio São José, de José Bonomi, em Campinas; no Sítio Santo Antônio, de Gumercindo Fadel, em Conchal, e na Fazenda Xingu, de Torashi Mine, em Ituverava. 
$(60 \mathrm{p}+60 \mathrm{~d}) ; 30 \mathrm{~kg} / \mathrm{ha}$, no plantio e $90 \mathrm{~kg} / \mathrm{ha}$, no desbaste $(30 \mathrm{p}+90 \mathrm{~d})$, e por fim $120 \mathrm{~kg} /$ ha de $\mathrm{K}_{2} \mathrm{O}$ no desbaste $(120 \mathrm{~d})$.

$\mathrm{Na}$ operação de plantio, o cloreto foi aplicado no sulco de semeadura, ao lado e abaixo do nível das sementes, em mistura com os adubos nitrogenado e fosfatado, conforme técnica recomendada por RIGHI et alii (14); quando cedido logo após a operação de desbaste, o cloreto foi jogado a lanço, em faixa junto às plantas, em mistura com o adubo nitrogenado e incorporado na operação de "chegar terra" à base das plantinhas remanescentes. Basicamente, foram aplicadas as doses de 10 e $60 \mathrm{~kg} / \mathrm{ha}$ de $\mathrm{N}$ e $\mathrm{P}_{2} \mathrm{O}_{\tilde{n}}$, no sulco de plantio, e efetuadas duas coberturas de $24 \mathrm{~kg} / \mathrm{ha}$ de $\mathrm{N}$, sendo que a segunda se deu no início do florescimento das plantas. Sulfato de amônio, superfosfato simples e cloreto de potássio foram os produtos utilizados.

Os canteiros experimentais constaram de quatro linhas de $5 \mathrm{~m}$ de comprimento, sendo as centrais consideradas úteis para a coleta de dados. As parcelas foram distribuídas em quadrado latino. Nos três primeiros anos, o plantio foi realizado com a variedade 'IAC 16' e, nos demais, com a 'IAC 17'.

No presente trabalho, são apresentados e discutidos os resultados de produção de algodão em caroço. Foram efetuadas análises individuais de variância e conjunta de todos os ensaios, e conjuntas para grupos de experimentos estabelecidos em função da resposta esperada do algodoeiro à aplicação de potássio. Para tanto, efetuaram-se diversos estudos de correlação entre índices de análise de solo e a produção relativa (PR) do tratamento testemunha, segundo RAIJ (13), que é dada pela fórmula:

$$
\mathrm{PR}=\frac{100 \times \text { (produção sem potássio) }}{\text { produção com potássio }}
$$

Combinando-se os estudos de correlação linear entre PR (calculada para a média dos tratamentos com $120 \mathrm{~kg} / \mathrm{ha}$ de $\mathrm{K}_{2} \mathrm{O}$ ) com os valores de $\left(\mathrm{Ca}^{2+}+\mathrm{Mg}^{2+}\right) / \mathrm{K}+\mathrm{e} 1 / \mathrm{K}^{+}$, da análise de solo, foram estabelecidos grupos de resposta esperada e, dentro deles, avaliado o efeito da aplicação parcelada do adubo potássico.

\section{RESULTADOS E DISCUSSÃO}

Os dados médios de produção de algodão em caroço, obtidos por tratamento em cada um dos dez experimentos, assim como os resultados de análises de variância individuais e conjunta, estão expostos no quadro 2.

Em apenas três ensaios (números 1,4 e 8 ), a testemunha (t) não diferiu estatisticamente de qualquer dos demais tratamentos ou, em outras palavras, em $70 \%$ dos casos o potássio proporcionou aumentos sensíveis na produção do algodoeiro. Nos experimentos de números 7 . 


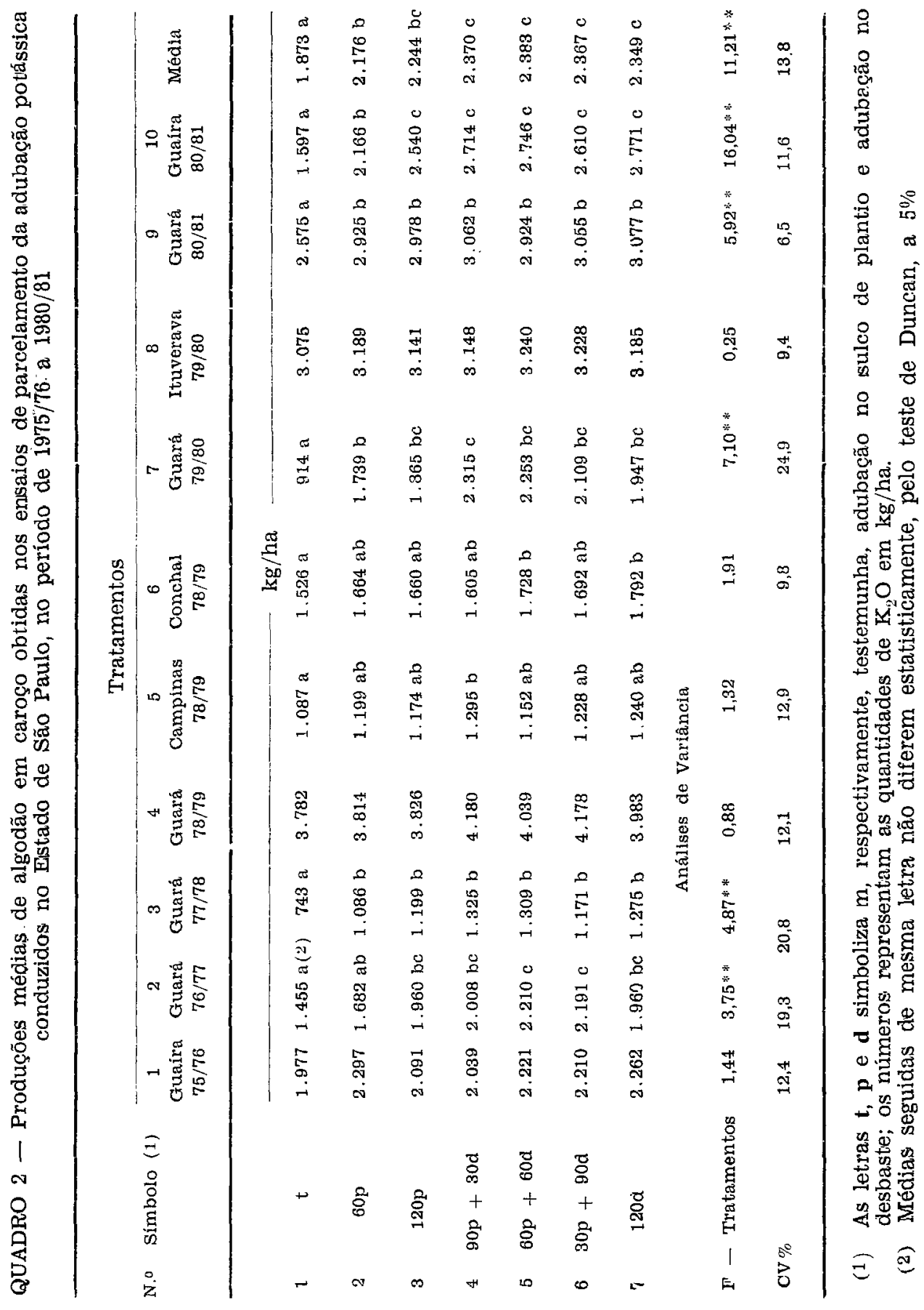


9 e 10 ( $30 \%$ dos casos), meia dose de potássio aplicada no sulco de plantio (60s) diferiu da testemunha (t), enquanto em um só caso a dose dupla aplicada no sulco (120s) suplantou a meia dose (ensaio 10). Com o parcelamento da dose máxima, observou-se efeito linear de potássio em $40 \%$ dos casos, a saber, nos ensaios de números $2,6,7$ e 10. Nas análises individuais, entretanto, as médias de produção obtidas corr as aplicações parceladas (tratamentos 4, 5 e 6), embora freqüentemente superiores, nunca diferiram estatisticamente das médias relativas a uma única aplicação, seja no plantio (120p), seja no desbaste (120d).

$\mathrm{Na}$ última coluna do quadro em questão, observa-se que no conjunto houve certo destaque para o parcelamento da dose máxima de adubo, uma vez que os tratamentos 4,5 e 6 diferiram estatisticamente de meia dose no plantio (60p), o que não se deu com o modo tradicional de aplicação de potássio (120p). Nem mesmo na análise conjunta, porém, a diferença de produtividade entre os tratamentos parcelados (números 4,5 e 6) e o usual (120p), em média de $6 \%$, alcançou significância estatística.

Retornando aos dados do quadro 1, nota-se razoável variação nos teores de $\mathrm{K}^{+}$revelados nas análises de solo, assim como nos valores calculados da relação $\left(\mathrm{Ca}^{2+}+\mathrm{Mg}^{2+}\right) / \mathrm{K}^{+}$. Uma vez que a reação do algodoeiro à adubação potássica frequientemente tem-se relacionado com o equilíbrio de bases no solo, conforme estudos de FREITAS et alii (4), FUZATTO \& FERRAZ (6) e SILVA (17), decidiu-se efetuar, no presente caso, um estudo de correlação entre os efeitos da aplicação de potássio sobre a produtividade das plantas e os resultados da análise de solo.

A princípio, admitiu-se a existência de uma relação linear entre a resposta do algodoeiro a potássio e alguns valores da análise de terra Para representar essa resposta da planta, foi considerada a produção relativa $(P R)$ do tratamento sem potássio $(t)$, calculando-a em função da produção dos diversos tratamentos adubados. No quadro 3 , são apresentados os valores do coeficiente de correlação simples (" $r$ ") obtidos nos diversos estudos.

Exceção feita ao cálculo dos valores de PR em função do trata. mento $6(30 p+90 d)$, nos demais casos o efeito de potássio se relacionou significativamente com a recíproca do valor de $\mathrm{K}^{+}$do solo $\left(1 / \mathrm{K}^{+}\right)$; os índices alcançados superaram, sempre, os obtidos no estudo com o valor direto de $\mathrm{K}^{+}$. No entanto, nota-se que os valores de " $r$ " foram sistematicamente maiores quando se considerou a recíproca da relação $\mathrm{K}^{+}$/ $\left(\mathrm{Ca}^{2+}+\mathrm{Mg}^{2+}\right)$, o que confirma a importância do equilíbrio catiônico do solo na disponibilidade de potássio para o algodoeiro, apontada antes nos trabalhos de FREITAS et alii (4), FUZATTO \& FERRAZ (6) e SILVA (17) Outros índices analíticos utilizados, como $\left(\mathrm{Ca}^{2+}+\mathrm{Mg}^{2+}\right), \mathrm{K}^{+} /$ $\left(\mathrm{Ca}^{2+}+\mathrm{Mg}^{2+}\right)$ e $\left.\mathrm{K}+/ \sqrt{\left(\mathrm{Ca}^{2+}+\mathrm{Mg}^{2+}\right.}\right)$, proporcionaram menores 


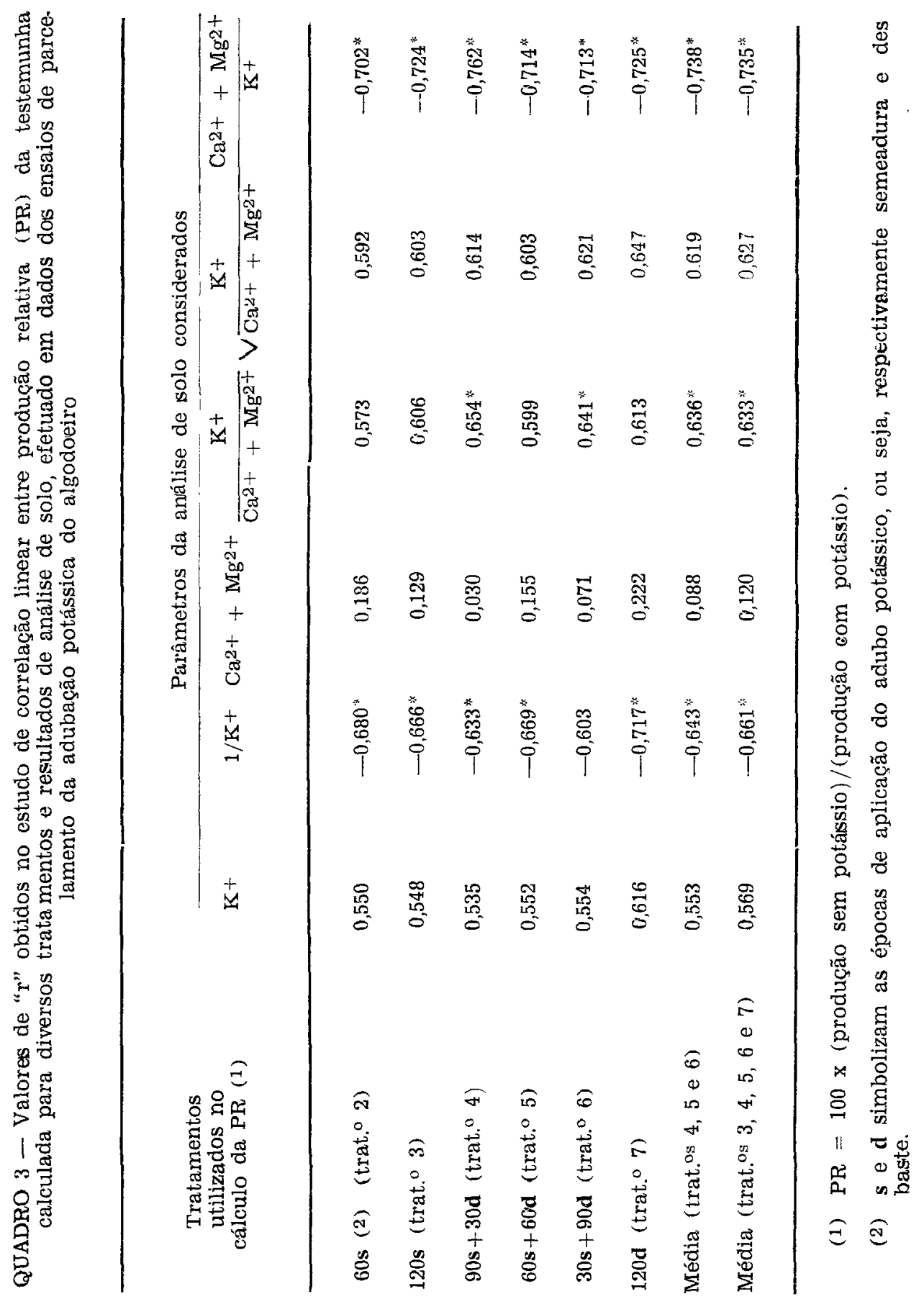


correlações. Considerando, ainda, que a variação nos valores de " $r$ " foi muito pequena dentro de cada caso, decidiu-se selecionar o estudo de correlação entre os indices $1 / \mathrm{K}^{+} \mathrm{e}\left(\mathrm{Ca}^{2+}+\mathrm{Mg}^{2+}\right) / \mathrm{K}+$ e os valores de PR calculados em função da média dos tratamentos adubados com o máximo de potássio (números 3, 4, 5, 6 e 7), para o estabelecimento de classes de respostas esperadas à adubação. As curvas de calibração correspondentes fazem parte da figura 1.

Foram adotados os limites padrões de 70 e $90 \%$ da PR, para a determinação das classes de fertilidade, conforme proposto por RAIJ (13). Combinando os dois estudos, no caso presente foram criadas as seguintes classes: a) classe de muito baixo teor de potássio no solo (com PR $<70 \%$ por, pelo menos, um dos critérios), englobando os ensaios 3,7 e $10 ;$ b) classe de baixo teor (com PR sempre entre 70 e $90 \%$ ), reunindo os ensaios 1, 2, 4, 5 e 9; c) classe de médio teor do nutriente (com PR $>90 \%$ por um dos critérios, pelo menos), composta dos ensaios 6 e 8. Realizaram-se, então, as análises conjuntas cujos resultados são apresentados nos histogramas da figura 2 .

Tendo em vista as produtividades alcançadas pela testemunha (t) nos diversos grupos, e os efeitos devidos à dose intermediária de $\mathrm{K}_{2} \mathrm{O}$ $(60 p)$, nota-se, por essa figura, que a reação do algodoeiro a potássio diminuiu do primeiro para o último grupo, relacionando-se perfeitamente com a disponibilidade do nutriente no solo. No entanto, mesmo no grupo de mais alta deficiência, a dose máxima de adubo cedida no sulco de plantio (120p) não superou estatisticamente a dose intermediária (60p), tendo provocado um acréscimo de produção não condizente com o esperado. Com efeito, enquanto $60 \mathrm{p}$ superou em $57 \%$ a produtividade da testemunha ( $t$ ), nesse grupo, foi $12 \%$ apenas o acréscimo observado de $60 \mathrm{p}$ para 120p. No grupo intermediário, tais aumentos foram $10 \%$ e $1 \%$, ao passo que, no de menor resposta, foram $6 \%$ e $-1 \%$ respectivamente.

Em trabalhos antigos, relatados por NEVES \& FREIRE (11) e SCHMIDT et alii (16), doses menores de $\mathrm{K}_{2} \mathrm{O}$ aplicadas em contato direto ou ligeiramente separadas das sementes, levaram a efeitos negativos da adubação sobre o desenvolvimento do algodoeiro. $\mathrm{Na}$ ocasiāo, tal fato foi atribuído a prejuízos sobre a germinação das sementes e sobre o crescimento inicial das raízës, consequientes đe maior concentração de sal no solo. Como no caso presente o adubo foi colocado ao lado e abaixo do nível das sementes, como preconiza a técnica recomendada por RIGHI et alii (14), admite-se que a influência negativa da alta concentração de cloreto $(\mathbf{1 2 0 p})$ tenha ocorrido ao nivel de crescimento inicial das raizes, embora nenhum sintoma externo se evidenciasse. Já a concentração de igual dose por ocasião do desbaste, tratamento 120d, aparentemente nāo prejudicou o algodoeiro, uma vez que a produtividade correspondente sempre esteve acima de 60p. 

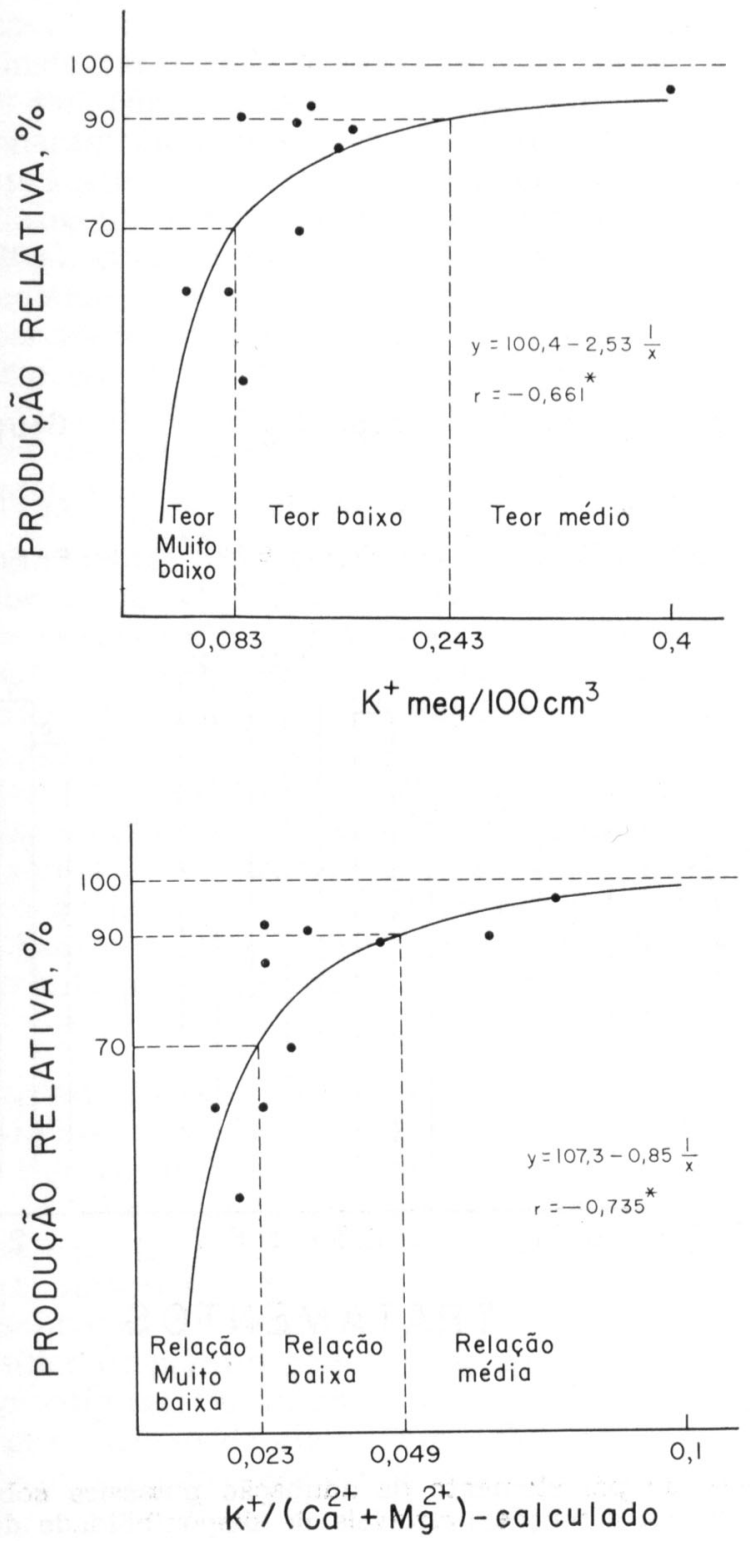

FIGURA 1 - Relação entre a produção relativa (100 x produção do tratamento sem potássio: produção média dos tratamentos com $120 \mathrm{~kg} /$ ha de $\mathrm{K}_{.2} \mathrm{O}$ ) e o potássio trocável do solo, à esquerda e, entre a produção relativa e a relação (cálcio + magnésio): potássio, à direita. 


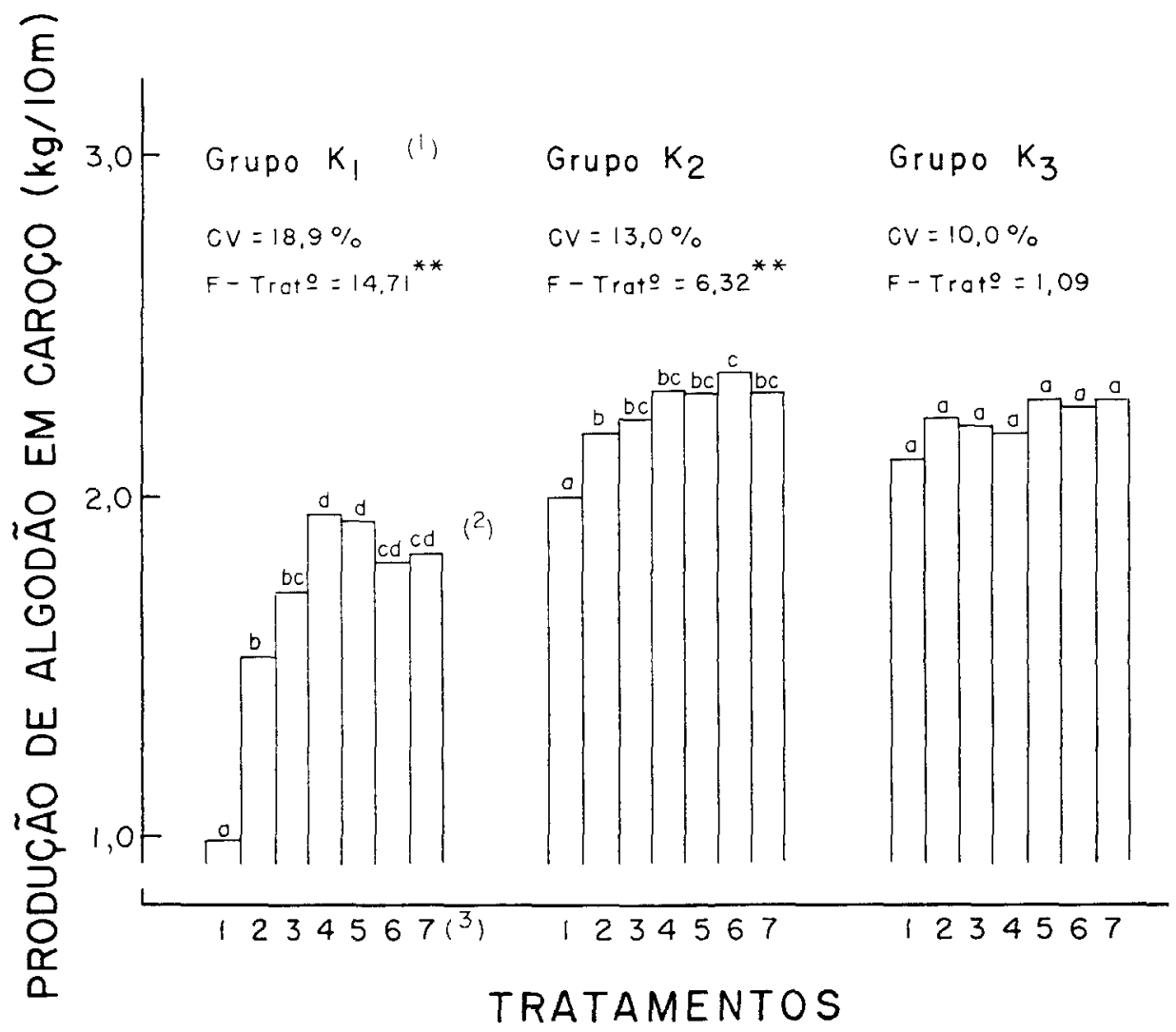

FIGURA 2 - Efeito do parcelamento da adubação potassica sobre a produção do algodoeiro em condições variáveis de disponibilidade do nutriente no solo.

(1) Grupos estabelecidos em função de $\mathrm{K}+$ do solo e da relação ( $\mathrm{Ca}+\mathbf{M g}$ )/ /K: $\mathrm{K}_{1}, \mathrm{~K}_{2}$ e $\mathrm{K}_{3}$, respectivamente de alta, média e baixa respostas esperadas.

(2) Teste de Duncan, a 5\%.

(3) Tratamentos $1,2,3,4,5,6$ e 7 , respectivamente com $0,60,120,90,60,30$ e $0 \mathrm{~kg} / \mathrm{ha}$ de $\mathrm{K}_{2 .} \mathrm{O}$ no plantio e, $0,0,0,30,60,90$ e $120 \mathrm{~kg} / \mathrm{ha}$ de $\mathrm{K}_{2} \mathrm{O}$ no desbaste. 
Quando aplicado parceladamente, nos solos mais deficientes, o cloreto de potássio proporcionou acréscimos lineares sobre a produção. No primeiro histograma da figura 2, pode-se observar que os tratamentos 90p + 30d, 60p + 60d e 30p + 90d, quando comparados com $60 p$, proporcionaram aumentos respectivos de $27 \%, 26 \%$ e $18 \%$, todos estatisticamente significativos. Além disso, $90 \mathrm{p}+30 \mathrm{~d}$ e $60 \mathrm{p}+60 \mathrm{~d}$ superaram estatisticamente o tratamento que simboliza a forma tradicional de adubar (120p), com aumento médio de $13 \%$ na produtividade. No grupo intermediário, o efeito do parcelamento foi menor, embora os tratamentos parcelados (números $4,5 \mathrm{e} 6$ ) tenham produzido $5 \%$ a mais de que 120p, em média. Ademais, pelo menos um dos parcelamentos $(30 p+90 d)$ superou estatisticamente aquele fornecedor de meia dose $(60 p)$, o que reforça a tendência para mais alta reação do algodoeiro à aplicação parcelada de potássio.

Aparentemente, tais resultados estão em desacordo com conclusões de trabalho de NEVES \& FREIRE (11), no qual se sugere que o adubo potássico seja todo colocado por ocasião do plantio, convenientemente separado das sementes. Nesse caso, entretanto, alguns aspectos devem ser esclarecidos. Em primeiro lugar, o referido estudo foi conduzido em condição de baixa resposta ao nutriente, razão talvez de não se observar efeito significativo de potássio sobre a produção do algodoeiro na quase totalidade dos ensaios. Os autores decidiram, então, sugerir que a adubação se fizesse por ocasião da semeadura, tendo em vista resultados de pesquisas conduzidas em outros países, até aquela oportunidade, bem como informações sobre o lento caminhamento do ion $\mathrm{K}^{+}$quando colocado superficialmente no solo, segundo KUPPER et alii (7).

$\mathrm{Na}$ verdade, para o estabelecimento da época e do modo de aplicação de adubos, como já exposto no início deste trabalho, devem-se considerar, ao lado da dinâmica do elemento no solo, também as exigências da planta. Já foi dito que o algodoeiro necessita de bom suprimento de potássio desde o início de seu desenvolvimento. Entretanto, há fases de mais intensa absorção do nutriente, durante o abotoamento e no início do florescimento. Considerando-se, ainda, que grande concentração de cloreto no sulco de plantio pode causar danos sérios à germinação ou às zaízes das plantinhas, ou mesmo que altas doses de potássio possam ser lixiviadas por excesso de chuva, em solos muito arenosos antes do seu efetivo aproveitamento, estaria justificada a necessidade do parcelamento de altas quantidades de adubo potássico.

Quanto às doses mais adequadas a serem aplicadas no plantio e no desbaste, pode-se observar, ainda na figura 2, uma tendência para $60 p+60 d$ estar, em qualquer dos grupos, entre os melhores tratamentos; nota-se, também, que uma dose maior no sulco $(90 p+30 d)$ se destacou apenas no grupo de solos deficientes. Dessa forma, no aguardo 
de estudos que possam particularizar mais as recomendações, sugere-se que o parcelamento das doses altas de $\mathrm{K}_{2} \mathrm{O}$, no caso de solos deficientes, se faça com a aplicação de $1 / 2$ a $2 / 3$ da dose necessária, no sulco de plantio, em faixa lateral e inferior à das sementes, e o restante em cobertura, após o desbaste, em mistura com o adubo nitrogenado, incorporando-se os adubos com a operação de "chegar terra" nas plantas. Tal procedimento, além de minimizar a perda por volatilização do nitrogênio, deverá possibilitar o maior aproveitamento do potássio, pelo enterrio do cloreto.

\section{CONCLUSÕES}

Do exposto neste trabalho, podem ser ressaltados os seguintes aspectos :

a) A produção relativa da testemunha ( $P R$ ), dada pela fórmula abaixo, expressou eficientemente a resposta do algodoeiro a potássio nos estudos de correlação com dados de análise de solo.

$$
\mathrm{PR}=\frac{100 \times(\text { produção sem potássio })}{\text { produção com potássio }}
$$

b) Nos estudos de correlação linear, a recíproca da relação $\mathrm{K}+/\left(\mathrm{Ca}^{2+}+\mathrm{Mg}^{2+}\right)$, calculada a partir de dados de análises de solo, foi o índice que melhor se relacionou com os valores de $P R$, o que mais uma vez demonstra a importância do equilíbrio de bases na disponibilidade do potássio para o algodoeiro.

c) No grupo de alta resposta esperada a potássio $\left(\mathrm{K}^{+}<0,08\right.$ meq. e $\mathrm{Ca}^{2+}+\mathrm{Mg}^{2+} / \mathrm{K}+>43$ ), o parcelamento na aplicação da dose de $120 \mathrm{~kg} /$ ha de $\mathrm{K}_{2} \mathrm{O}$ superou o modo tradicional de adubação no sulco, em termos de produtividade das plantas.

d) No grupo de média resposta esperada ( $\mathrm{K}^{+}$, entre $0,08 \mathrm{e}$ 0,24 meq. e, $\mathrm{Ca}^{2+}+\mathrm{Mg}^{2+} / \mathrm{K}+$, na faixa de 2043 ), notou-se clara tendência para também maior efeito da aplicação parcelada.

e) Para o cultivo do algodoeiro em solos deficientes em potássio, é recomendado que a aplicação de cloreto de potássio se faça de forma parcelada, aplicando-se $1 / 2$ a $2 / 3$ da dose necessária no sulco de plantio (ao lado e em nível inferior ao das sementes), e o restante em cobertura, após o desbaste, junto com o adubo nitrogenado, com incorporação da mistura na operação de "chegar terra". 


\section{SUMMARY}

\section{EFFECT OF SPLIT APPLICATION OF POTASSIUM CHLORIDE IN COTTON}

The advantage of split application of potassium chloride in cotton was studied in ten field experiments, conducted at different localities during the period of 1975 to 1981 . In such cases, doses of 0,60 and $120 \mathrm{~kg} / \mathrm{ha}$ of $\mathrm{K}_{2} \mathrm{O}$, were placed in a fillet beside and below the seeds, at planting. In other treatments $1 / 3$. $1 / 2,2 / 3$ or the total quantity of the highest level of potassium fertilizer was applied together with nitrogen, just after thinning, in a side-dressing operation. and covered slightly by subsequent cultivation. When all the $K$ was applied at planting, linear effect on cotton yield appeared only in $10 \%$ of the experiments. This proportion increases to $40 \%$ when split applications were made. However. in combined analysis of all tests no significant difference was found between the two methods. Based in a study of simple correlations between cotton produc. tivity and potassium application expressed as the control treatment's relative yield and indices of soil analysis like $1 / \mathrm{K}^{+}$and $\left(\mathrm{Ca}^{2+}+\mathrm{Mg}^{2+}\right) / \mathrm{K}^{+}$, three groups of experiments were established, according to different expected responses. Considering the group of high expected responses $\left[\mathrm{K}<0.08 \mathrm{meq}\right.$ and $\left(\mathrm{Ca}^{2}+\div\right.$ $\left.+\mathrm{Mg}^{2+}\right) / \mathrm{K}^{+}>43 \mathrm{~J}$, parcelled application resulted in increases of cotton yield when compared with the normal method of application. Similar tendency was observed in the group of intermediate expected responses [0.8-0.24 meq of $\mathrm{K}+$ and $20-43$ of $\left.\left(\mathrm{Ca}^{2}++\mathrm{Mg}^{2+}\right) / \mathrm{K}+\right]$. In potassium deficient soils split application of potassium chloride can be recommended, $1 / 2$ or $2 / 3$ of the total level furnished at planting and the remainder just after thinning, by side-dressing, mixed with nitrogenous fertilizer and followed by cultivation.

\section{REFERÊNCIAS BIBLIOGRAFICAS}

1. CATANI, R. A. Estudos do potássio nos solos do Estado de São Paulo São Paulo, Companhia Brasileira de Potassa e Adubos Indústria e Comércio, 1955. $39 \mathrm{p}$.

2. COOPER, H. P. \& WALLACE, R. W. The rate and time of applying potash fertilizers to cotton. South Carolina, Agric. Exp. Sta. Annual Report 50:127-128, 1937.

3. EATON. F. M. \& ERGLE, D. R. Mineral nutrition of the cotton plant. Plant Physiology, 32:169-175, 1957.

4. FREITAS, L. M. M.; MCCLUNG, A. C.; GOMES, F. P. Determinação das áreas deficientes em potássio para a cultura de algodão. Fertilité, 26:37-47, 1966 .

5. FUZATTO, M. G. Adubação mineral. In: CULTURA e adubação do algodoeiro. São Paulo, Instituto Brasileiro de Potassa, 1966. p.475-508.

6. \& FERRAZ, C. A. M. Correlação entre o efeito da adubação potássica no algodoeiro e análise química do solo. Bragantia, Campinas, 26:345-352, 1967.

7. KÜPPER, A.; GROHMANN, F.; GARGANTINI, H. Movimento de ions $\mathrm{NO}_{3}$, $\mathrm{NH}_{4}^{+}, \mathrm{K}+$ e $\mathrm{PO}-{ }_{4}$, em solo massapê, roxo misturada e arenito Bauru. Campinas, Instituto Agronômico, 1953. 8p. (Boletim, 34) 
8. McCANTS, C. B. Seasonal distribution of nutrients in soil under tobacco culture. Soil Science, 94:36-43, 1962.

9. MENDES, H. C. Nutrição mineral. In: CULTURA e adubação do algodoeiro. São Paulo, Instituto Brasileiro ce Potassa, 1966. p.461-474.

10. NEVES, O. S. \& FREIRE, E. S. Adubaçăo do algodoeiro. I. Influência dos adubos, quando aplicados em contacto com as sementes, sobre a germinação. Bragantia, Campinas, 15:301-314, 1956.

11. _ _ Adubação do algodoeiro. IV. Ensaios sobre época de aplicação de azoto e potássio. Bragantia, Campinas, 16:269-296, 1957.

12. OLSON, L. C. \& BLEDSOE, E. P. The chemical composition of the cotton plant and the uptake of nutrients at different stages of growth. Georgia, Exp. Sta., 1942. (Bulletin, 222)

13. RAIJ, B van. Técnicas de avaliação da fertilidade do solo e estabelecimento de níveis de adubação. In: AVALIACÃO DA FERTILIDADE DO SOLO. Piracicaba, Instituto da Potassa \& Fosfato e Instituto Internacional da Potassa, 1981. p.49-74.

14. RIGHI, N. R.; FERRAZ, C. A. M.; CORREA, D. M. Cultura. In: CULTURA e adubação do algodoeiro. São Paulo, Instituto Brasileiro de Potassa, 1966. p.255-317.

15. ROUSE, R. D. Potassium requiriments of crops on Alabama soils. Alabama, Agr. Expt. Sta., 1960. (Bulletin, 324)

16. SCHMIDT, W.; NEVES, O. S.; FREIRE, E. S. V. Ensaios com azoto, fósforo e potássio em "campos de cooperação". Bragantia, Campinas, $17\left(27^{7}\right): 363-409,1958$.

17. SILVA, N. M. Importância da seleção de glebas para estudos de adubação do algodoeiro. Campinas, Instituto Agronômico, 1971. 11p. (Projeto BNDE/ANDA/CIA - Publicação, 8)

18. - FERRAZ. C. A. M.; GRIDI-PAPP, I. L.; CIA, E.; RODRIGUES FILHO, F. S. O. Adubação nitrogenada e potássica do algodoeiro no Estado de São Paulo. Resultados de produção no período de 1970 a 1973. Bragantia, Campinas, 24(10):177-193, 1975. 